\title{
THE CONTEMPORARY WORLD - MILITARY, STRATEGIC AND RELATED ASPECTS
}

\author{
Prof. Charles Burton Marshall
}

\section{Basic Concepts: War, Strategy, Power:}

The focus of this symposium is on strategic matters. My task in this initial presentation deals with the ratios of power in the contemporary world. That word, power, occurs frequently in the discussion of international affairs. Its meaning is not an obvious one, nor are the meanings of most of the other terms which predominate in the discussion of international affairs obvious. I think it advisable, therefore, to clarify some of the basic terms pertinent to the topic.

War is definable as a contest of purpose between two sides consisting of groups which are states, or at least aspire to act like states. To the extent of exercising exclusive control over a segment of territory, the two sides dispose armed forces. They seek, each to its own advantage, to prevail in the contest of purpose by bringing about a radical redress in relative capa. city and will for bringing force to bear. To that end they must actually transmit energy and discharge it destructively against each other's establishments.

From that simple definition, we can derive many interacting dimensions which determine whether wars are relatively larger or smaller. In this connection I wish to avoid the phrase limited war. It seems to me to be a misleading phrase. No war is infinite. All wars are limited. What is significant is the question of the respects in which a particular war is enlarged or constricted. How many participants are there? What purposes are put at issue as war aims? How far do the antagonists go in generating energy and in producing organization and paraphernalia for transmitting such energy and expending it against the adversary with destructive effect - that is to say, to what level do they mobilize? How much energy is employed destructively? Over how wide an area? How intensively? How long is the effort persevered in? How great is the havoc wrought? These questions indicate the various interacting dimensions of war, and I should stress that the interactions, 
depending on particular circumstances, may be expansive or constrictive.

I take note also of various categories of warfare encompassed by the definition I have given. Wars may be distinguished, one from another, with respect to the relation between the territorial bases and perimeters claimed by the contending sides. If they are mutually exclusive, the war concerned is unequivocally an international war. If they coincide, or if the territorial base asserted by one encompasses the base asserted by the other, the war is unequivocally an internal war. In particular cases, wars may be of mixed characteristics in this respect. The question of whether a war is to be regarded as internal or international may express the central issue at stake between the contending sides. Another point of distinction relates to the extent to which the antagonists are disposed or are able to conform to the usages generally followed by well developed states engaged in war. How explicit are their boundaries, especially in the consciousness of the inhabitants who dwell on one side or the other of the demarcation lines? How far are their armed forces professionalized - that is to say, distinguished by vocation and dress from the general public? To what extent do the antagonists have formal means of announcing policies and issuing edicts? With respect to such matters as these, wars may be differentiated as conventional or unconventional.

I wish to proceed now to consider the meaning of strategy and the cognate word strategic. As a point of convenience for clarification I ask you to take account of the meaning of the word weapon. A weapon is an instrument used at the last stage of a perhaps complex series of stages involved in the process of generating and transmitting energy, and, finally, bringing it to bear destructively on an enemy establishment. That is to say, a weapon is an instrument used in the final stage of discharging force on a target in combat. When we focus narrowly on the junctures where weapons are used in warfare, our perspective is tactical. When, in contrast, we adopt a perspective in which we seek to see the whole set of relations among the material factors and between them and the myriad less concrete factors which bear upon war, our perspective is strategic. Strategy encompasses the great array of what I have called the interacting dimensions of war. What are the war 
aims? How do they relate to the question of who shall be drawn in as participants, and vice versa? How will these matters affect the scope, intensity, and duration of the conflict? How, in reverse, will these matters affect the issues put at stake? And so on, through a complex of inter-relations. These are the constituents of strategy, which encompass all of the military aspects of war but is by no means limited to them.

One more distinction between tactics and strategy is worth mentioning. Tactical considerations relate to combat. Strategic concepts are continuously active, whether or not war is actually being engaged in. Every government must, to some extent, be continuously involved in the calculus of conceptual war, even at times when formal peace obtains. In his interesting small book called War in the Modern Age, Sir Keith Hancock stresses the understanding of war and peace as continuous processes unremittingly exacting attention, resources, and moral concern from those who govern. He tells us that they are not properly to be considered as successive and mutually exclusive segments of experience. He regards them as interactive and complementary endeavors which must be pursued in the life of states. How much of moral concern and of material resources must be portioned to the uses of civil enjoyment? How much must be diverted to those uses which are designed to intimidate and deter potential enemies and, as a corollary, to generate confidence in continuity within the state and to give reassurance to those abroad who are disposed to stand with it? Even under the conditions of peace, statesmanship involves an unremitting appraisal of the potential for conflict and of its probable consequences and an appraisal as well of the reciprocal estimates made by putative friends and enemies over the great globe. These are the continuing constituents of any national strategy. Such strategy, if it is adequate, must continuously look to the generating and maintenance of material and moral factors to assure that such appraisals shall be made with self-confidence.

We come now again to the concept of power. That basic term refers to capacity to achieve intended results. In international affairs it takes on a strategic tone. It rings with implications relevant to capacity to intimidate putative enemies and to reassure potential friends. The constituents of power in international affairs do not pertain exclusively to a regime's horizontal relationships with other regimes, nor do they 
pertain exclusively to relationships between a regime and its internal base. Rather, the constituents of power encompass both frames. More to the point, the elements of power concern continuous interaction between the internal life of an organized society and the vast realm external to it. The relevant factors include such concrete matters as resources, numbers, and geographic position. They include the aggregate of talents available within the population and such non-material matters as public spirit and general esprit among the people. Other constituents pertain to a regime's reputation - its prestige, its capacity to elicit confidence in its given word, its will and its ability to enter into and to keep contracts. A central consideration is always the integrity of the regime's position in relation to the society over which it exerts jurisdiction. Is the regime legitimate? Is it such that those who exercise authority do so in confidence of their right to do so and in confidence that that right is acknowledged by determining numbers of those over whom they exercise jurisdiction? In contrast, is the regime unsure of its title to authority and anxious about its tenure and its standing with its people? Those and such considerations are integral to the quotients of power in international affairs.

The elements of power are so basic to the life of states that the term for the attribute is often applied to the entity; states are often called powers. Those considered to be capable of exerting influence widely beyond their own spans of jurisdiction are referred to as great powers, and great powers regarded as of prime magnitude are often called super powers. I urge that we apply caution in employing these terms. The role of a great power or a super power is not simply that of exercising influence over a wide span. It is also that of being looked to expectantly and of continuously being pressed by others into the assumption of obligations on their behalf. It is so easy to infer that the career of a great power is that of pushing others this way or that and to forget that the role is also a good deal of being pulled this way and that by others. As a companion point, it is so easy to infer that a so-called great power disposes illimitable efficacy and that whatever may be unsatisfactory in the world situation is accordingly due to a default of policy on the part of a great power. I urge upon you the thought that even a so-called great power 
does not have power to ordain and to control affairs beyond the span of its own jurisdiction.

A year or so ago I spent a long evening discussing foreign policy with a highly select and manifestly capable group of young persons in my own country. At the outset they all agreed, when one of them uttered an aphorism about the need for the United States to eschew the role of a global policeman. My comment to them was that such an aphorism - an editoral writer's phrase rather than a policy maker's phrase - never really settles any issue. As the evening progressed, however, the participants pressed a series of questions such as why the United States had permitted the Greek colonels to overturn Greece's so-called democracy, why the United States had not headed off the 1967 war between Israel and its neighbors, and why the United States did not put its foot down and enforce a settlement of the Kashmir issue, race problems in Southern Africa, and so on. By tone and implication, the United States had complete foresight and untrammeled authority in world affairs. I pointed out to that audience that if the United States really had such omniscience and omnicompetence, then it would have no right not to be the world's policeman. I reminded them of the simple and self evident circumstance that, for any government, including my own, foreign policy pertains to those matters which by definition lie beyond the span of its jurisdiction.

Since coming to South Africa on this third visit, I have several times encountered similar suppositions about American power in the world. Only a few weeks ago a South African reproachfully asked me why the United States had not long ago laid down the law with respect to affairs within China. Twenty years ago, he contended, the United States should have formulated and given effect to a solution of the China problem, thereby avoiding a store of trouble for itself. I pointed to the vastness and complexity of the problem and to the modesty of American purchase on the situation. He retorted that my country disposed illimitable power and that it would have achieved any result that it wished if only it had had a mind to do so. Ten minutes further along in the discussion the focus was on Rhodesia. My friend asked me why the United States did not come to its senses regarding Rhodesia's autonomy. He added that there was no possibility of bringing about a col- 
lapse of the regime there so long as it continued to enjoy South Africa's support. Taking my cue from what had been said about China, I retorted with a suggestion that the United States might issue South Africa a demand for a change of front. In retort my friend expostulated that South Africa was an independent and autonomous country far beyond reach of American fiat. He abandoned all the premises he had invoked only a few minutes before.

\section{Shift and polarization of power relations}

Here, however, I am getting ahead of my account. I am discussing the ratios of power in the contemporary world without having first examined the antecedent circumstances. Until very recently a basic circumstance in world affairs was the pre-eminence of Europe. It would be more accurate to say that certain countries or nations of Europe were ascendant in world affairs, for Europe is a general region rather than being itself an actor on the world stage. That region, consisting of two compound peninsulas at the northwest extreme of the great land mass of the eastern hemisphere along with the nearby British Isles, was the location from which radiated the energies and impulses by which the whole globe was drawn into one span of cognition in a great historic process beginning about five centuries ago. Conceivably, some other region might have been the hub of the great outward movement which encompassed the globe, but in fact the hub was Europe. Where the American nation's Declaration of Independence asserts a claim to a "rightful station among the powers of the earth", it expresses a purpose to overthrow subordination and to enter into the scheme of diplomacy on a parity with the governments of Europe, where the powers of the earth were then located. Europe's heyday came in the century between Waterloo and Sarajevo. The nations then dominant in world affairs drew upon a common fund of history. They shared a universe of discourse - meaning not merely that they understood each other's languages, but also that in a broad sense they shared a common view of the nature of reality. The leading states of Europe were then roughly of the same magnitude. Their governments had come at last to accept a hands-off principle with respect to each other's internal affairs. The appeal of ideology 
was at a low point. That is to say, none of the world leaders was then trying to coerce any of the others into compliance with some purported universal scheme for the future. Their wars, fought for modest stakes, were relatively infrequent, brief, and not very destructive. Great Britain, exercising naval pre-eminence from its offshore position, served as a balancing factor among the continental powers.

In retrospect, that period from Waterloo to Sarajevo - a period from which many of our assumed norms about world affairs, including our standards of diplomatic practice and the still enduring notion that peace and order are inherent conditions in world relations and that violence and disorder are aberrant - seems almost idyllic. The process of disintegration, however, had begun toward the end of the nineteenth century and gathered momentum in the early phases of the twentieth. One distinguishing circumstance was the loosening of the bonds which had held together the multinational imperial states of Europe. Another circumstance related to the emergence of an integrated German state in central Europe. Its size was disproportionate to the old European balance. Its power was enhanced by the dynamic development of ferrous industry in the latter part of the nineteenth century. Germany was disposed to challenge Great Britain's pre-eminence at sea in addition to seeking continental pre-eminence. The result was the precipitation of two general wars a generation apart.

From the perspective of the present we now understand the two World Wars as being two stages of one great historic process. In each instance the state of weapon technology had an aggravating effect. The wars set in motion proved to be beyond the capacity of the European powers themselves to bring to resolution. In his book, The Struggle for the Mastery of Europe, A. J. P. Taylor emphasizes the importance of the winter of 1917 as the juncture when it was manifested that the European powers had become incapable of settling their issues among themselves. We can say that for the next thirty years that is from 1917 until the immediate sequel to World War II - the process of registering this circumstance dominated world affairs. As of 1910 one would probably have counted eight major powers in world affairs - five of them entirely within the compass of Europe and a sixth one, namely Russia, stretching from eastern Europe across the face of Asia. Forty 
years later the major powers were reduced to two - namely Soviet Russia and the United States, the latter located entirely beyond the confines of Europe.

The shift in power relations over the world, brought about in so brief a period, was enormous. This polarization between two positions lying outside the former center of pre-eminence in world affairs had been long foreseen. Baron Stein, a diplomat serving Catherine II of Russia in the late eighteenth century, was perhaps the first to predict it. Alexis de Toqueville, Heinrich Heine, and many others foresaw the development in the early decades of the nineteenth century. How basic the change in circumstances has been for the United States! It can be indicated by one point of reference. In that summer of 1914 , when the various European governments were going through the fateful decisions and responses which would bring on the first of the World Wars, none of the governments concerned appears to have given a moment's thought to the question of the United State's possible role in the hostilities then impending. Nothing indicative of awareness of the American potential, at least, has come to light from the diplomatic archives.

\section{Other factors of change}

How the United States has responsed to the demands of a pre-eminent role which has been thrust upon it by circumstances is a story which I shall not recount in detail here. You well know the earlier hopes for achieving on a worldwide scope, through the agency of a universal organization based on the principle of collective security, an order equivalent to that which prevailed in the nineteenth century. You are aware how, in face of immediate disappointment of that hope in the sequel to World War II, the United States engaged its energies in fashioning an array of regional alliances in pursuance of which it has undertaken strategic commitments far and wide over the globe. It is relevant to cite at this point some of the concomitant circumstances differentiating the contemporary world from the situations obtaining in antecedent stages.

A circumstance which comes readily to mind concerns the erosion of the imperial-colonial arrangements through which the former great states of Europe exercised their autho- 
rity over peoples of diverse cultures in positions far removed. Those inequalitarian arrangements have vanished wholesale. By dozens and dozens former colonial areas have spun into independence and statehood. Many of them now participate in the public life of the world without having much of a public life of their own. They participate in the making of history on the world scene without having any relevant fund of history of their own to draw upon. As a result, busybody tendencies are encouraged among nations the world over. Governing apparatuses which can scarcely give effect to policies within their own realms are tempted to demonstrate their efficacy by meddling in matters beyond their jurisdiction. States which have never experienced a free election of their own become the insistent exponents of free elections in lands thousands of miles away.

Another complicating factor relates to the intensification and acceleration of contemporary communications. In a poet's words:-

Gone are the days when madness was confined

By seas and hills from spreading through mankind,

When though a Nero fooled upon a string,

Wisdom still reigned unruffled in Peking.

Americans might well envy the conditions obtaining in an earlier phase of the national career when Thomas Jefferson, our first Secretary of State, made note that two years had passed since any communication had come in from our envoy in Madrid and that the matter might require a looking-into if much more time should elapse in silence from that quarter. In our time the U.S. Department of State receives about three-quarters of a million words of electronic communication from abroad in each day of operations. No one mind can begin to master it all. Proliferation of information is only one aspect of the problem. Even more important is the stimulation of artificial exigency. Statesmanship must contend everlastingly with the question whether problems coming to the fore abroad are inherently urgent or are only made to appear urgent because of the speeding up of communications. Some problems in world affairs are inherently urgent. Questions of that sort may arise in our personal lives. When one hunts doves, for example, he must learn to respond to stimulus in a moment. If he asks a com- 
mittee to inquire and to report whether the birds aloft really are doves, he will have missed his opportunity. In contrast, a question of what sort of life insurance to buy or what stocks to invest in is one to be answered with mature deliberation. A person who is deliberate in face of questions requiring impulsive answers and quick in coming up with answers to problems requiring deliberation is likely to get his life disorganized. So it is with governments which cannot distinguish between the truly urgent problems and problems only seemingly so in world affairs. I have in mind the fatuous speed with which the governments, though lacking any real grasp of the situation, made up their minds on whether and how to act in face of the so-called crisis in the Congo of eight years ago - a fallacious decision entered into with undue haste under the stimulus of modern communications.

A third distinguishing circumstances, as Hannah Arendt says in her book, On Revolution, is the rampancy of political ideas which echo the French revolution of the eighteenth century. One of these, closely identified with secular rationalism, is the idea that psychic fulfillment is to be achieved through mass political activity. We are supposed to find salvation in temporal affairs. Our relationship to the state or to the collectivity is supposed to bring us spiritual regeneration. This is an age of faith - not of the faith that moves mountains, but of the faith that mounts movements. According to a premise widely prevailing, all things are made feasible by capturing the center of political authority and issuing edicts for whatever may be desired. "Seek ye first the political kingdom and all else will be added unto you", is the way one former political leader on the continent of Africa expressed the thought. One of the prominent activists in my country recently declared that he was tired of the pursuit of happiness and that it was up to the government to capture it and turn it over to him bound.

A closely linked circumstance is the appeal of ideology. I mentioned that term before. I said that ideology was at a low ebb in international affairs during the nineteenth century. At that time it was on the margins of politics. In our time it is a central consideration. The ideological approach to general affairs has had a power base in international politics for more than a half century. By ideology I do not mean simply an array of strongly affirmed political beliefs or preferences. 
The term pertains to political purposes which purport to rest on a systematic intellectual basis. Ideological beliefs purport to have universal validity. They purport to be an interpretation of all history, to be predictive of an inevitable future, and to be exclusively valid for all humanity. Ideological beliefs are maintained not as prudential possibilities but as certitudes of quasi-religious character. Ideologues are characterized by their claims to exclusive legitimacy. All differentiated purposes and all interests which diverge from those maintained by the ideological proponents are regarded not merely as rival preferences but as deviations from the very laws of reality. Despite all that has been said about the mellowing of ideology in recent years, we see today the proof of the continuing dogmatic thrust of ideology in the events now being reported from Czechoslovakia.

Still another differentiating circumstance of great significance is the contemporary dynamism of technology. Alfred North Whitehead once observed that the invention of invention was itself the greatest of all inventions. We see the significance of that observation if we interpret invention in a broad sense so as to include the tendency in contemporary life, especially within the most advanced societies, to contrive ever new methods of production and organization. The dynamic effects are given pointed emphasis in Jean-Jacques Servan-Schreiber's new book, The American Challenge. I can only take time to recommend it to your attention. I can not take all the time that would be required to cover the enormous important implications of the book as it relates the way in which modern education has surpassed even the importance of natural resources and the importance of the investment process as a factor in the momentum of development of contemporary societies. The data which he adduces open up a prospect of an ever-widening gap between the rate of performance and the level of economic benefit of the most successful societies and those of the laggard societies in the contemporary world. The gap between the successful and the less successful societies is all too likely to become wider and wider as the future unfolds.

\section{Technology of war and weaponry}

I do not wish to dwell on these speculative considerations, however. I do wish to stress the effects of contemporary tech- 
nology on weapons. As you know, the course of battle in World War I was largely determined by the advantage accruing to the tactical defensive as a result of the state of weapon technology at that time. In World War II the state of weapon technology shifted the advantage to the offensive. In the closing stage of that war the power of the offensive was pushed right through the top of the graph by the tapping of nuclear energy as a means of destructive power in war. Also in that war and since, there were prodigious developments in respect of lengthening the radius of attack. The consequence of these combined developments is to bring the whole world within the compass of one strategic theater. The prodigious weapons of our time are continuously ready for instant use. The nations with enough economic resources to be able to afford these new weapons systems are, so to speak, continually in a state of mobilization. The launching of an attack of enormous magnitude against an adversary is an ever instant possibility. Yet it is a trait of these weapons that they cannot be used to fend off an attack. In this respect they differ vitally from the major weapons systems of preceding epochs. Battleships and army divisions were susceptible of being used to defend one's own perimeter as well as for impinging upon an enemy's perimeter, but this is not the case with the prodigious weapons of our time. The concept of a deterrence - that is, forefending against attack by having in place a retaliatory capability so great as to be able to destroy the enemy even if one's own establishment is destroyed first - carries strategic thought into a new dimension.

Along with their destructive potential, one must also take account of the strategic limitations of the prodigious weapons. They have become so powerful that they scarcely can be factored into any rational calculation for waging war. The only strategic mission that can plausibly be assigned to them is that of countervailing and neutralizing similar weapons disposed by an adversary. I emphasize this point. Several times since my arrival in South Africa $I$ have been pressed with questions as to why the United States has not brought its nuclear weaponry to bear to achieve some policy objective or another. It is important to keep in mind the limitations on the utility of nuclear weapon systems. It is necessary for the United States to maintain them lest some determining advantage should ac- 
crue to its adversaries, but that negative purpose sums up the benefits.

Here again I should stress the dynamic effect of invention. According to a widely prevalent idea all processes have been accelerated in contemporary times. The idea is an exaggeration. To the contrary, some processes have been lengthened and retarded as a direct result of the speeding-up of others. The celerity characteristic of modern means of attack has a concomitant in the lengthening of the time required for producing a new system of weaponry. Invention becomes the mother of necessity. The leading military powers are pressed to move ahead with ever new weapon systems lest some determinative advantage should accrue to the other side. The power to forge ahead in the technology of war has become a basic element in strategic calculations.

With all these manifold changes, a longing for the realization of a dependable order encompassing the globe - an upto-date and more enduring prototype of the order which characterized the nineteenth century - persists widely. It is a speculative question whether such an order can be realized again within the calculable future. I take account of the many recurring predictions that mankind as a whole will soon succeed in relegating warfare to the unhappy past and therewith enter upon an unprecedented era of general peace. I see no empirical evidence to sustain this high hope. I am not predicting that the hope will be frustrated. I am simply disclaiming any reason for feeling assured of its success. 